\title{
Interictal behaviour in hospitalised temporal lobe epileptics: relationship to idiopathic psychiatric syndromes
}

\author{
DAVID BEAR, KENNETH LEVIN, DIETRICH BLUMER, DIEDRE CHETHAM, JOHN \\ RYDER
}

From the McLean Hospital and Behavioral Neurology Unit, Beth Israel Hospital, Department of Psychiatry, Harvard Medical School, Boston, Massachusetts, USA

SUMmARY Temporal lobe epileptics undergoing psychiatric hospitalisation were contrasted with patients suffering idiopathic psychiatric syndromes or other epilepsies. Quantitative ratings from blind interviews conducted according to a protocol confirmed the appearance of a statistically distinctive behavioural profile, including the desire for social affiliation, circumstantiality, religious and philosophic interests, and deepened affects, among the temporal lobe epileptics.

For more than a century, investigators have chronicled the association of psychiatric symptoms and epilepsy. ${ }^{1-4}$ More recently, a pattern of alterations in behaviour, emotionality, and intellectual preferences has been described during the interictal period in patients with, specifically, temporal lobe epilepsy. ${ }^{2}$ Characteristics ascribed to temporal epileptics include deepening of mood and affect, aggressive irritability, reduction or modification in sexual interests, perseverative preoccupation with details, and intensification of religious or cosmologic concerns with possible paranoid interpretations. ${ }^{23} \mathrm{~A}$ prior study has documented the frequent occurrence of this cluster of behaviours among unselected temporal epileptics attending outpatient epilepsy clinics. The characteristic interictal behaviours, assessed either by self reports or third person ratings, were present to a greater extent among the temporal epileptics than among matched controlled subjects or patients with other neurological diseases. ${ }^{2}$

While many temporal epileptics sampled in this and other studies had not undergone formal psychiatric treatment or hospitalisation, a significant number of patients in virtually all surveys have independently come to psychiatric attention..$^{3-5}$ Frequently assigned psychiatric diagnoses include

Address for reprint requests: David M Bear, MD, Behavioral Neurology Unit, 330 Brookline Avenue, Boston, MA 02215, USA.

Received 10 September 1981 and in revised form 14 December 1981

Accepted 25 January 1982 impulse discontrol and aggressivity, mood disorder, and schizophreniform psychosis. ${ }^{4-8}$

In this study, we have attempted to determine whether specific behavioural features might distinguish temporal lobe epileptics admitted to a psychiatric hospital from other patients with similar behavioural characteristics: those with aggression, affective disorder, or idiopathic schizophrenia. To investigate the specific contribution of the temporal lobes to the interictal behavioural pattern, temporal epileptics were also contrasted with hospitalised patients suffering non-limbic seizure disorders. We used an interview sampling specific features of behaviour which previously discriminated temporal lobe epileptics from normal subjects or other neurologic patients. ${ }^{2}$ Additional qualitative observations concerning aggressive behaviour, sexual preference, alteration in mood, and thought disorder were included as behavioural variables.

\section{Methods}

Fourteen behavioural characteristics representative of the interictal behaviour syndrome previously reported in temporal lobe epilepsy ${ }^{2}$ were assessed by means of 37 independently coded interview observations. These summary traits and the constituent observational items are listed in table $1 \mathrm{~A}$ and $1 \mathrm{~B}$, respectively.

Each patient participated in a structured interview confined to the variables in table 1 , which was conducted by two psychiatric interviewers unaware of the subject's assigned psychiatric diagnosis or neurological status. Interviews were tape-recorded and reviewed periodically to confirm that no inquiries concerning seizure phenomena or 
psychiatric diagnosis had been made. Following the interview which lasted approximately one hour, each examiner independently completed the 37 item evaluation summarised in table 1B. Concordance between the two observers was greater than $90 \%$. In the infrequent cases of discrepant ratings, the average of the two scores was used for analysis.

For comparison of group profiles, the 37 behavioural ratings were combined to yield scores on the 14 summary traits. The group profiles of trait scores were subjected to two-way analysis of variance (Anova) with groups as an independent factor and traits as repeated measures. Since a significant difference was found between the temporal epileptics and each of the comparison groups (main group effect), identification of specific discriminating interview items was carried out by repeated one-way analyses of variance.

Research assistants randomly selected and encoded diagnoses for subjects in the study, drawing patients from those who had undergone electroencephalographic examination while hospitalised at the McLean Psychiatric Hospital in Belmont, Massachusetts. Patients with previously diagnosed structural brain lesions or below average intelligence were excluded, as were repeated users of psychedelic drugs. All subjects were between the ages of 15 and 69 years. Five groups of 10 subjects each were assembled, with an attempt to match age and sex distribution, according to the following criteria:

Temporal lobe epileptics patients had EEGs clearly diagnostic of temporal lobe epilepsy (unequivocal spiking from nasopharyngeal or temporal leads) and a documented history of complex partial seizures. The average age at onset of seizures was 15.0 years. Although many of these patients were known to be epileptic at the time of hospitalisation, most were admitted for psychiatric problems initially considered independent and had an average of 1.5 prior psychiatric admissions. There were six men and four women with median age of 29 years.
Other epileptics patients had EEGs diagnostic of epilepsy outside the temporal lobes (generalised or focal) on at least two occasions, and had a documented history of seizures not of the complex partial type. The average age at onset was 14.5 years, and patients averaged 1.2 prior psychiatric hospitalisations. There were five men and five women with median age of 27 years.

Schizophrenics patients had normal EEGs and were diagnosed by all attending psychiatrists—usually a resident, ward supervisor, and a staff physician-as suffering a schizophrenic psychosis according to the criteria of DSMII. ${ }^{9}$ Five patients demonstrated paranoid tendencies; the remaining five were considered simple or mixed schizophrenics. The group had an average of 1.3 prior psychiatric hospitalisations. There were six men and four women with median age of 26 years.

Primary affective disorders patients had normal EEGs and were diagnosed by all treating psychiatrists as suffering primary affective disorder, bipolar type. ${ }^{9}$ Five patients in the group were interviewed in the manic phase, and five in the depressed. Patients had an average of 1.5 prior psychiatric hospitalisations. There were five men and five women with median age of 26 years.

Aggressive character disorders patients had normal EEGs and were diagnosed by all treating psychiatrists as suffering one of the following disorders: borderline personality $(N=5)$, schizoid personality $(N=2)$, sociopathic personality $(\mathrm{N}=2)$ and adolescent adjustment reaction $(\mathrm{N}=1)$. Aggression and poor impulse control were problems common to the patients in the group. The group had an average of 1.1 prior psychiatric hospitalisations. There were six men and four women with median age of 23 years.

Differences among these groups in age, sex, or years of education were not significant (chi-square test), although the character disorder group tended to be younger. No correlation of these variables with any behavioural trait achieved statistical significance.

Table 1 Behavioural variables assessed by interview

A Summary characteristics

Characteristics

Clinical definitions*

\section{Affects}

Emotionality, euphoria

Sadness

Aggressivity

Sexual alterations

Paranoia

Intellectual interests

Religiosity

Philosophical interests

Hypermoralism

Hypergraphia

Dispositional characteristics Obsessiveness

Viscosity

Guilt

Humourless sobriety

Circumstantiality
Deepening of emotions, sustained intense affect; mood swings; euphoric episodes

Discouragement, tearfulness; self-deprecation; suicidal thoughts or acts

Problematic temper, irritability, rage attacks, overt violence to people or objects

Loss of libido, hyposexualism; hypersexuality; fetishism, transvestism, exhibitionism

Generalised suspicions; over inclusive interpretation of motives and events; paranoid delusions

Holding deep religious beliefs, often idiosyncratic; multiple conversions, cosmic consciousness

Nascent metaphysical or cosmological preoccupations

Attention to rules with inability to distinguish significant from minor infractions; preoccupation with moral dilemmas; punitive zeal

Keeping of extensive diary, detailed notes; writing autobiography or novel

Orderliness, compulsive attention to detail, ritualism, perseveration

Excessive social cohesion or interpersonal clinging; tendency to draw out interpersonal encounters

Self-scrutiny, recrimination, harsh self-judgment

Overgeneralised ponderous concerns; humour lacking or idiosyncratic

Excessive attention to peripheral detail in speech or writing 
Table 1 -continued

B Constituent observations

\begin{tabular}{|c|c|c|c|}
\hline \multicolumn{2}{|c|}{ Observation } & \multirow{2}{*}{$\frac{0}{\text { insi }}$} & 5 \\
\hline 1 & $\begin{array}{l}\text { Aggressive outbursts as a characteristic: } \\
\text { Nature of aggressive outburst: }\end{array}$ & & $\begin{array}{l}\text { very important } \\
\text { typically physical }\end{array}$ \\
\hline 3 & $\begin{array}{l}\text { Nature of aggresstve outburst: } \\
\text { Physical outbursts are: }\end{array}$ & directed invariably to objects & directed typically against people \\
\hline 4 & Outbursts are: & rare & frequent and regular \\
\hline 5 & Role of outbursts in hospitalisation: & not a factor & the main factor \\
\hline $\begin{array}{l}6 \\
7\end{array}$ & $\begin{array}{l}\text { Sentiment towards outburst after the fact: } \\
\text { Outbursts are: }\end{array}$ & $\begin{array}{l}\text { substantial remorse } \\
\text { spontaneous or set off by minor }\end{array}$ & $\begin{array}{l}\text { no remorse } \\
\text { associated with identifiable }\end{array}$ \\
\hline & & irritants & $\begin{array}{l}\text { provocations } \\
\text { independent of alcohol }\end{array}$ \\
\hline $\begin{array}{l}8 \\
9\end{array}$ & $\begin{array}{l}\text { Outbursts are: } \\
\text { Frequency and severity of outbursts }\end{array}$ & $\begin{array}{l}\text { typically associated with alcohol } \\
\text { has lessened recently }\end{array}$ & $\begin{array}{l}\text { independent of alcohol } \\
\text { has increased and worsened } \\
\text { recently }\end{array}$ \\
\hline $\begin{array}{l}10 \\
11 \\
12\end{array}$ & $\begin{array}{l}\text { Patient's response to outbursts in retrospect is to: } \\
\text { The patient, following outbursts, tends to: } \\
\text { Objects of outbursts: }\end{array}$ & $\begin{array}{l}\text { accept responsibility } \\
\text { claim amnesia for outbursts } \\
\text { tend to be the same people }\end{array}$ & $\begin{array}{l}\text { deny responsibility } \\
\text { remembers outburst } \\
\text { could be anybody who disturbs } \\
\text { the patient }\end{array}$ \\
\hline 13 & Outbursts are: & $\begin{array}{l}\text { typically associated with } \\
\text { persecutory thoughts }\end{array}$ & $\begin{array}{l}\text { independent of persecutory } \\
\text { thoughts }\end{array}$ \\
\hline 14 & The patient exhibits: & $\begin{array}{l}\text { a meticulous sense of right and } \\
\text { wrong }\end{array}$ & $\begin{array}{l}\text { an indifference to issues of right } \\
\text { and wrong }\end{array}$ \\
\hline 15 & The patient has: & $\begin{array}{l}\text { a number of significant, stable } \\
\text { relationships }\end{array}$ & no stable relationships \\
\hline $\begin{array}{l}16 \\
17 \\
18\end{array}$ & $\begin{array}{l}\text { The patient exhibits moral indignation: } \\
\text { The patient is: } \\
\text { The patient: }\end{array}$ & $\begin{array}{l}\text { exclusively towards others } \\
\text { preoccupied with religious matters } \\
\text { typically interprets experiences in } \\
\text { global or philosophical terms }\end{array}$ & $\begin{array}{l}\text { exclusively towards self } \\
\text { indifferent to religious issues } \\
\text { displays no philosophical } \\
\text { orientation }\end{array}$ \\
\hline 19 & The patient: & $\begin{array}{l}\text { likes to keep a diary and record } \\
\text { experiences or to write poetry, etc }\end{array}$ & $\begin{array}{l}\text { displays no interest in writing } \\
\text { things down }\end{array}$ \\
\hline 20 & The patient: & $\begin{array}{l}\text { does not perceive self as an } \\
\text { unhappy person }\end{array}$ & $\begin{array}{l}\text { perceives self as unusually sad and } \\
\text { depressed }\end{array}$ \\
\hline 21 & The patient: & $\begin{array}{l}\text { sees self as someone who changes } \\
\text { mood easily and frequently }\end{array}$ & $\begin{array}{l}\text { denies rapid changes in mood as } \\
\text { characteristic }\end{array}$ \\
\hline 22 & The patient: & $\begin{array}{l}\text { finds the same things humorous } \\
\text { that most people would }\end{array}$ & $\begin{array}{l}\text { exhibits an idiosyncratic sense of } \\
\text { humour }\end{array}$ \\
\hline $\begin{array}{l}23 \\
24\end{array}$ & $\begin{array}{l}\text { The patient: } \\
\text { The patient daydreams and fantasises: }\end{array}$ & $\begin{array}{l}\text { often finds things amusing } \\
\text { frequently }\end{array}$ & $\begin{array}{l}\text { finds few things humorous } \\
\text { rarely }\end{array}$ \\
\hline 25 & The patient has sexual fantasies: & rarely & frequently \\
\hline 26 & The patient reports: & no change in sexual fantasies & $\begin{array}{l}\text { significant change in the content of } \\
\text { fantasies at an identifiable time }\end{array}$ \\
\hline 27 & $\begin{array}{l}\text { The patient reports, with regard to the frequency of } \\
\text { sexual fantasies: }\end{array}$ & recent increase & recent decrease \\
\hline 28 & $\begin{array}{l}\text { The patient reports, with regard to the frequency of } \\
\text { sexual experiences: }\end{array}$ & recent increase & a recent decrease \\
\hline 29 & $\begin{array}{l}\text { The patient reports, regarding the nature of sexual } \\
\text { experiences: }\end{array}$ & no recent change & recent significant changes \\
\hline 30 & The patient reports self to be: & sexually very active & sexually inactive \\
\hline 31 & The patient is: & $\begin{array}{l}\text { preoccupied with orderliness and } \\
\text { detail }\end{array}$ & indifferent to orderliness and detail \\
\hline $\begin{array}{l}32 \\
33 \\
34 \\
35 \\
36\end{array}$ & $\begin{array}{l}\text { The patient exhibits: } \\
\text { The patient exhibits: } \\
\text { The patient exhibits: } \\
\text { The patient presents as: } \\
\text { The patient exhibits: }\end{array}$ & $\begin{array}{l}\text { no viscosity } \\
\text { much perservation } \\
\text { no circumstantiality } \\
\text { very sad } \\
\text { very little insight into character and } \\
\text { problem }\end{array}$ & $\begin{array}{l}\text { substantial viscosity } \\
\text { no perservation } \\
\text { much circumstantiality } \\
\text { not notably sad } \\
\text { substantial insight }\end{array}$ \\
\hline 37 & The patient: & denies hallucinations & has experienced hallucinations \\
\hline
\end{tabular}

${ }^{*}$ Reference 2 documents the original clinical observations which suggested these categories.

\section{Results}

TEMPORAL LOBE EPILEPTICS CONTRASTED WITH COMBINED PSYCHIATRIC GROUPS

Patients with temporal lobe seizures $(\mathrm{N}=10)$ were first contrasted with the non-epileptic, combined psychiatric group composed of schizophrenic, affective and character disorder patients $(N=30)$. In fig 1 , mean scores on the 14 summary trait variables are plotted in order of decreasing significance of the difference between the two groups. The vertical axis is centred on the mean of the entire patient sample (0); each unit deviation represents one standard error of the mean.

Overall, temporal lobe epileptics were rated higher for the presence of interictal behaviour characteristics than the other psychiatric patients ( $p<0.001)$. Temporal epileptics achieved higher scores on 13 of the 14 summary traits. Each of the first seven comparisons in fig 1 attained statistical significance. The summary traits which most powerfully differentiated temporal lobe epileptics from a 


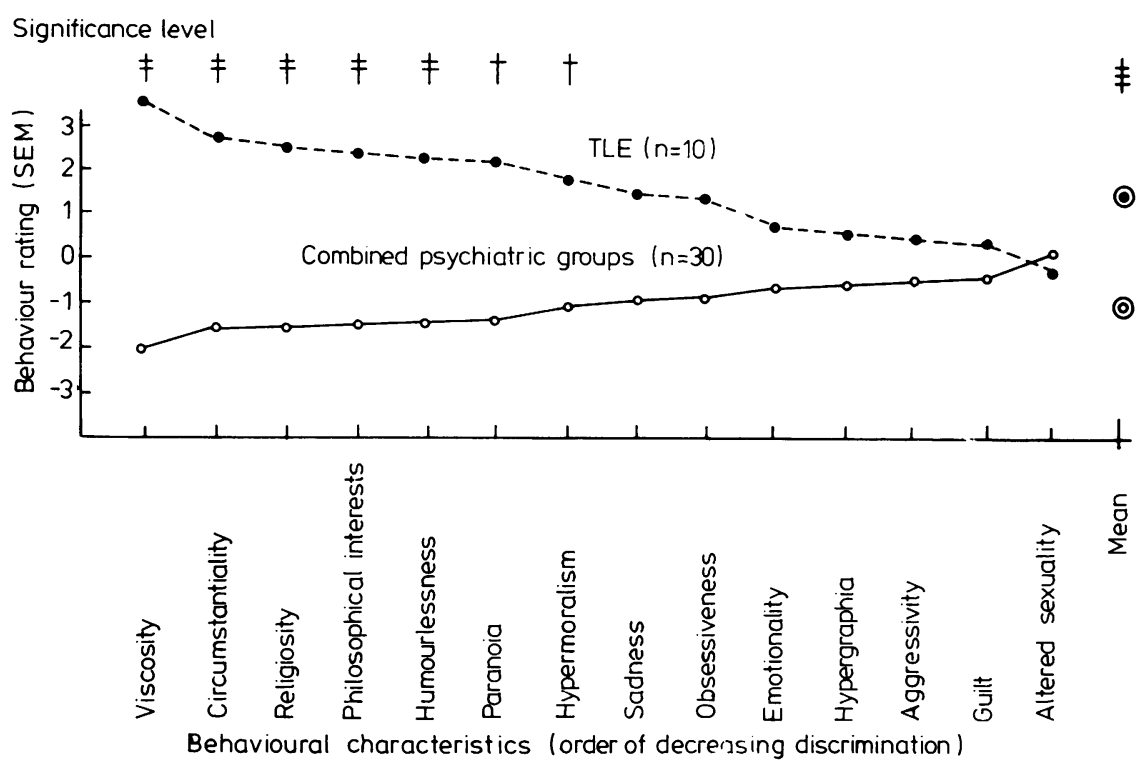

Fig 1 Temporal lobe epileptics contrasted with combined psychiatric groups. Ordinate: 0 represents the mean behaviour rating for all patients; each unit is a standard error of the mean (SEM). Abscissa: behavioural traits listed in order of decreasing discrimination. Significance of differences (Anova): $\neq p<0.001, \ddagger p<0.01, \dagger p<0.05$. For definition of behavioural variables and discussion, see table 1 and text. Profiles were significantly different at the 0.001 level.

mixed psychiatric group were excessive interpersonal clinging (viscosity*), repetitive preoccupation with peripheral details (circumstantiality), religious and philosophical preoccupations, humourless sobriety, tendency to paranoid over-interpretation, and moralistic concerns.

To clarify similarities and differences between the interictal behaviour syndrome of temporal lobe epilepsy and specific psychiatric syndromes, individual comparisons between the temporal lobe epileptics and character disorder, affective disease, and schizophrenic groups were next performed.

\section{TEMPORAL LOBE EPILEPTICS CONTRASTED WITH} CHARACTER DISORDERS

Observations which differentiated temporal lobe epileptics from patients with aggressive character disorders are summarised in table 2 . Temporal lobe epileptics were distinguished most powerfully by the more frequent appearance of religiosity, viscous and circumstantial behaviour, bizarre humour, and philosophic interests. Over all sampled behaviours,

*The term viscosity has been used in the past to describe both a stickiness of thought processes and an enhanced interpersonal adhesiveness. We have attempted to observe these behaviours independently, distinguishing characteristics of thought recorded as obsessiveness or circumstantiality from the quality of interpersonal cohesiveness, which is our operational definition of viscosity. See also table 1 . the profiles differed at the 0.001 level (ANOVA).

Many patients in the character disorder group were hospitalised for recurrent aggressive disturbances. This may account for the finding that temporal lobe patients actually experienced fewer aggressive outbursts than character disorder patients. More revealing, however, were the qualitatively different features of aggression. The temporal lobe patient was more likely to accept responsibility for his anger, not relying on the claim of amnesia or irresistible impulse. Religious and moral concerns, so prominent in the temporal lobe sample, reached the lowest values in the character disorder group, affording a clear differentiation of the interictal

Table 2 Temporal lobe epileptics contrasted with character disorder group

\begin{tabular}{llcl}
\hline Rank & Discriminating observations & ${ }^{*} F^{18}$ & p value \\
\hline 1 & Religiosity & 22.96 & 0.001 \\
2 & Viscosity & 12.97 & 0.01 \\
3 & Decrease in angry outbursts & $10 \cdot 10$ & 0.01 \\
4 & Bizarre humour & 9.87 & 0.01 \\
5 & Circumstantiality & $8 \cdot 61$ & 0.01 \\
6 & Philosophical interest & 7.51 & 0.05 \\
7 & Accepts responsibility for angry & & \\
& outbursts & 6.20 & 0.05 \\
8 & Moralism & 5.84 & 0.05 \\
\hline
\end{tabular}

*One-way Anova. 
behaviour syndrome from aggressive character disorder.

TEMPORAL LOBE EPILEPTICS CONTRASTED WITH AFFECTIVE DISORDERS

Despite statistical overlap on measures of intensified affect, temporal lobe epileptics could be distinguished from patients with affective disorders on the basis of aberrant humour, circumstantiality, viscosity, and religiosity (table 3 ). Paranoia, a prominent characteristic of the hospitalised temporal lobe epileptic group, was rarely observed in patients with affective disorder. The greater appearance of interictal characteristics among temporal lobe epileptics, reflected in the mean profiles, distinguished the two groups ( $p<0.01$, ANOVA).

In contrast to the character disorder group, patients with affective disorder received low ratings of aggressivity. For this reason, the presence of angry outbursts, physical attacks, and a significant role of anger in hospitalisation were reliable identifying features of the temporal lobe epileptics contrasted with the affective disorder patients (table 3 ). Among the alterations in sexual behaviour explored during the interview, an overall decrease in sexual interest-thought, fantasy, and behaviour-was more common in the temporal lobe group. Temporal lobe epileptics were also judged to have less insight into their behaviour than the patients with affective disorder.

\section{TEMPORAL LOBE EPILEPTICS CONTRASTED WITH} SCHIZOPHRENICS

In the comparisons of hospitalised patients with temporal lobe seizures and idiopathic schizophrenics, there were many behavioural overlaps: altered emotionality, paranoia, aberrant humour, religious and philosophic preoccupation. However, based on profile level over all traits, the interictal behaviour cluster was more frequent among temporal lobe epileptics $(p<0.01$, ANOVA). Viscosity was the single most distinctive feature among the temporal lobe epileptics (table 4). A tendency to prolong interpersonal contact with the interviewer, often suggesting warmer affects, contrasted with social awkwardness and flat or bizarre affects of the schizophrenic subjects. A propensity to write extensively-diaries, notebooks, novels, or biographies - was rarely seen among schizophrenic patients. This feature of the interictal behaviour syndrome - often distinctive for the cosmological or moral tone of the writing - was more frequent in the temporal lobe group. Alterations in sexual behaviour occurred in both groups. Frequency of intercourse was more reduced among schizophrenics but decreasing intensity of all sexual interests,
Table 3 Temporal lobe epileptics contrasted with affective disorder group

\begin{tabular}{clcc}
\hline Rank & Discriminating observations & ${ }^{*} F^{18}$ & $p$ value \\
\hline 1 & Bizarre humour & 17.37 & 0.001 \\
2 & Circumstantiality & 13.99 & 0.01 \\
3 & Paranoid outbursts & 12.79 & 0.01 \\
4 & Viscosity & 11.92 & 0.01 \\
5 & Less insight into own behaviour & 10.31 & 0.01 \\
6 & Angry outbursts & 8.65 & 0.01 \\
7 & Social isolation & 7.81 & 0.05 \\
8 & Role of overt anger in & 7.07 & 0.05 \\
& hospitalisation & 6.28 & 0.05 \\
10 & Physical outbursts & 6.05 & 0.05 \\
11 & Religiosity & 5.96 & 0.05 \\
12 & Decreased sexuality & 5.25 & 0.05 \\
\hline
\end{tabular}

*One-way Anova.

including self stimulation and fantasy, distinguished the temporal lobe epileptics.

Comparison of several forms of aggressivity did not reveal differences between the two groups. This was not due to an absence of aggressivity in the temporal lobe group, as comparison with the affective disorder patients had revealed, but to substantial aggressiveness among the schizophrenic patients. Contrasted with "aggressive" psychiatric groups, character disorder or schizophrenic, the temporal lobe patients were actually distinguished by fewer angry outbursts. Impulse discontrol as an isolated feature of behaviour thus had little value in distinguishing temporal lobe epilepsy from other psychiatric groups.

TEMPORAL LOBE EPILEPTICS CONTRASTED WITH OTHER EPILEPTICS

The comparison of temporal lobe epileptics with other seizure patients undergoing psychiatric hospitalisation is summarised in fig 2 . Viscosity and circumstantiality as well as obsessive features appeared frequently in the other-epileptic group and thus were not statistically differentiating. However, the characteristic intellectual preoccupationsreligiosity and philosophic interest-were more frequent in the temporal lobe group. Furthermore, deepened affects, reflected both in the patient's experience and the observer's determination of sad-

Table 4 Temporal lobe epileptics contrasted with schizophrenia group

\begin{tabular}{llcl}
\hline Rank & Discriminating observations & ${ }^{*} F^{18}$ & $p$ value \\
\hline 1 & Viscosity & 8.60 & 0.01 \\
2 & Hypergraphia & 6.65 & 0.05 \\
3 & Less reduction in frequency of & & \\
& sexual intercourse & 5.45 & 0.05 \\
4 & Less sexual intensity & 5.32 & 0.05 \\
5 & Decrease in angry outbursts & 5.01 & 0.05 \\
\hline
\end{tabular}



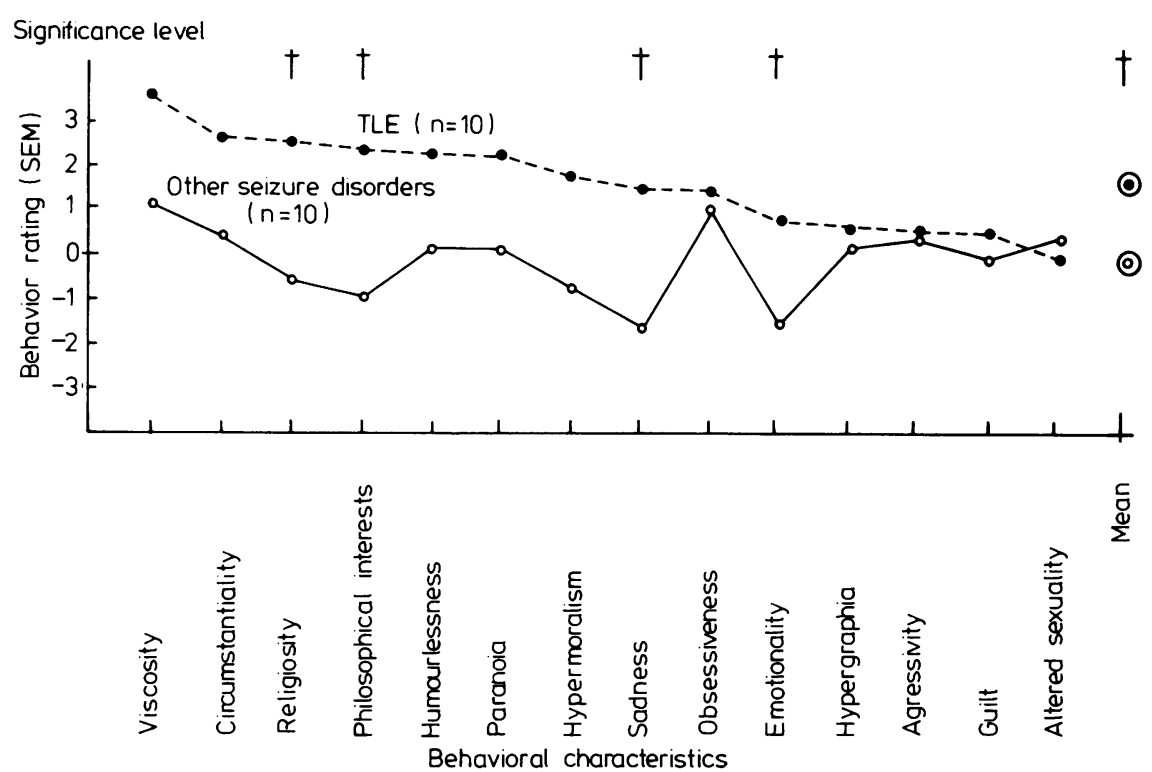

Fig 2 Temporal lobe epileptics contrasted with other seizure disorders. Axes and notations as indicated in fig 1. Profiles were significantly different at the 0.05 level.

ness and in ratings of emotionality, were least noted in the other-epileptic group but most common among the temporal lobe patients. Intensity of aggression did not differ between the two groups, but temporal lobe patients experienced fewer overt outbursts.

\section{Discussion}

Since the present study sampled patients in the course of psychiatric hospitalisation, these results cannot provide additional information about the prevalence of behavioural changes among the ambulatory temporal-lobe or other epileptic populations. They do, however, clarify qualitative differences between the behavioural profile of the hospitalised temporal lobe epileptic and other inpatient groups.

Despite the selection factor of psychiatric hospitalisation, the behavioural profile of the temporal epileptic patients was markedly similar to previous characterisation of ambulatory temporal lobe epileptics. In a prior study, the presence of viscosity, circumstantiality, and philosophic interest allowed accurate discrimination of temporal lobe epileptics from normal subjects or patients with other neurologic diseases. ${ }^{2}$ The present study provides confirmation of an interictal behaviour syndrome in temporal lobe epilepsy which includes features of affect (deepening emotion, aggressivity), thought (philosophic, religious, and moralistic interests), and behaviour (viscosity, circumstantiality). The appearance of these behaviours in concert distinguished the temporal lobe epileptic from other psychiatric patients, as well as from normal or neurologically impaired subjects.

Temporal lobe epileptics requiring psychiatric hospitalisation might be expected to represent a subpopulation with severe behavioural changes. In fact, questionnaire profiles from the hospitalised group (to be reported independently) were elevated compared to previous ambulatory samples. In seeking for neurological factors that might correlate with severity of the interictal behaviour syndrome, we note that nine of ten hospitalised patients exhibited bilateral independent spike discharges during electroencephalography. In a previous investigation using similar behavioural variables, only patients with unilateral temporal lobe spikes were studied; $67 \%$ of these patients had not undergone psychiatric hospitalisation. ${ }^{2}$ These results are consistent with reports of more severe cognitive $^{10}$ and psychiatric ${ }^{112}$ impairments in patients with bilateral temporal lobe foci.

The current results both support the concept of a distinct interictal behaviour syndrome in temporal lobe epilepsy and provide the clinician with specific features which differentiate it from superficially similar psychiatric syndromes. In overall comparison of temporal lobe epileptics with the non-epileptic 
psychiatric groups, the most powerful distinguishing features were viscosity-defined in this study as interpersonal adhesiveness-and circumstantiality. The tendency of the epileptic patient to cling to the examiner and generally to draw out social encounters had been noted by Kraepelin and many subsequent observers. ${ }^{3}$ This social clinging may have a localisable anatomical substrate, since specific lesions in the limbic system increase or decrease social cohesiveness in animals. ${ }^{1319}$

Aggression is often emphasised as a presenting behavioural feature in temporal lobe epilepsy. While confirming significant aggression among temporal lobe patients, this study revealed distinguishing features between aggression in the setting of the interictal behaviour syndrome and aggression in character disorders. The temporal lobe patient was less likely to have undirected angry outbursts, more likely to respond to real environmental provocation with planned, consciously directed acts, more likely to accept responsibility for these acts without a claim of amnesia, and more likely to feel subsequent guilt. Deepening of emotion with mood swings, depression, suicidal attempts, and, more rarely, euphoric episodes are features of both the interictal behaviour syndrome ${ }^{237}$ and bipolar affective disease. ${ }^{9}$ However, the temporal lobe epileptic could be distinguished behaviourally from the patient with affective disorder on the basis of viscosity, circumstantiality, aggression, paranoid tendencies, and lack of insight into illness.

Schizophreniform psychosis is perhaps the most frequently cited behavioural complication of temporal lobe epilepsy. ${ }^{6}$ In fact, it occurs in a minority of temporal lobe epileptics and represents an advanced stage of the more common interictal behaviour changes. ${ }^{23}$ However, it is not surprising that a subset of temporal lobe patients undergoing psychiatric hospitalisation would include patients with paranoid features and thought disorder resembling the behaviour profile of schizophrenia.

Viscosity, an attempt to draw out social contact, was the clearest differentiating feature of the temporal lobe epileptic compared to the idiopathic schizophrenic. Since social cohesion involves communication of warm interpersonal affects, this finding is consistent with the observations of Beard et $a^{6}{ }^{6}$ that affects are better preserved in the schizophreniform psychosis of temporal lobe epilepsy than in idiopathic schizophrenia.

Qualitative differences in sexual behaviour also distinguished the temporal lobe epileptic and schizophrenic groups. While frequency of intercourse was more reduced among schizophrenics, possibly secondary to confinement or medication, the overall intensity of sexual interest, including fan- tasy and self-stimulation, was more diminished among the temporal lobe epileptics. The previously reported hyposexuality of the temporal lobe epilep$\mathrm{tic}^{14}$ thus includes thoughts and fantasies as well as overt behaviour. This may prove a useful differentiating point, since abstinent schizophrenics often develop elaborate sexual fantasies.

The final comparison, between temporal lobe epileptics and patients with other seizure disorders, provides quantitative evidence of an interictal behaviour syndrome specific to temporal lobe epilepsy. Many investigations have suggested that behaviour disorder or psychiatric hospitalisation is more common among temporal lobe than other epileptics. ${ }^{45}$ In a careful study of causes for psychiatric hospitalisation in epilepsy, temporal lobe epileptics were found to suffer persistent interictal psychoses while patients with other seizure disorders were frequently admitted for acute, toxic confusional states. ${ }^{15}$

The present study, drawing both groups from a hospitalised population, is the first to evaluate specific behavioural features. Viscosity and circumstantiality, the strongest differentiators of temporal lobe epileptics from the non-epileptic psychiatric groups, were found frequently among other seizure patients. This finding raises several possibilities: these behaviours may be a non-specific consequence of epileptic seizures, or of anti-convulsant therapy, or may result from involvement of anatomical structures activated by epileptic foci either inside or outside the temporal lobes.

While the current results do not resolve this question of mechanism, we and others have observed several patients with temporal lobe spike foci who, in the absence of clinical seizures or anticonvulsant therapy, developed a characteristic interictal behaviour syndrome, including viscosity and circumstantiality. Furthermore, several investigators have reported an inverse correlation between severity of behavioural effects and frequency of clinical seizures. $^{7}$ Thus, interictal activation of specific anatomic structures rather than the occurrence of seizures or administration of anticonvulsants likely underlies the behavioural changes. ${ }^{23}$

Although viscosity and circumstantiality did not statistically differentiate the epileptic groups, changes in thought (religious and philosophical interests) and affect (emotionality, mood swings, depression) were more frequent among temporal lobe epileptics. Thus, the characteristic cluster of interictal behaviours was uniquely found in temporal lobe epilepsy. This is consistent with a previously proposed mechanism relating the interictal behaviour syndrome to newly formed, fortuitous limbic (emotional) associations established by an 
epileptic focus within the temporal lobe. ${ }^{2316}$

We are grateful to the staff of McLean Hospital for the opportunity to examine patients under its care, for financial support, and for technical assistance, especially that provided by Dr Norman Mintz and Dr Eugene Doroff. Dr Paul Fedio and Mr David Van Sant of the National Institute of Health supplied computational assistance, and Professor Robert Rosenthal of Harvard University and Dr Kenneth Adams of the Henry Ford Hospital, Detroit, provided statistical consultation. Dr Normal Geschwind and Dr Arnold Mandel brought the possible relevance of the septal cohesion effect to our attention.

\section{References}

' Waxman SG, Geschwind N. Hypergraphia in temporal lobe epilepsy. Neurology (Minneap) 1974;24:629-36.

${ }^{2}$ Bear DM, Fedio P. Quantitative analysis of interictal behavior in temporal lobe epilepsy. Arch Neurol 1977;34:454-67.

${ }^{3}$ Bear DM. Temporal lobe epilepsy: A syndrome of sensory-limbic hyperconnection. Cortex 1979;15: 357-84.

${ }^{4}$ Gibbs EL, Gibbs FA, Fuster B. Psychomotor epilepsy. Arch Neurol Psychiat 1948;60:331-9.

${ }^{5}$ Davison K, Bagley C. Schizophrenia-like psychosis associated with organic disorders of the cental nervous system. Br J Psychiatry 1969;4:113-84.

- Slater E, Beard AW. Schizophrenia-like psychoses of epilepsy. Br J Psychiatry 1963;109:95-150.

${ }^{7}$ Flor-Henry P. Schizophrenic-like reactions and affective psychoses associated with temporal lobe epilepsy: etiological factors. Am J Psychiatry 1969;126:400-3.
${ }^{8}$ Ervin FR, Epstein AW, King HE. Behavior of epileptic and non-epileptic patients with temporal spikes. Arch Neurol Psychiat 1955;74:488-97.

${ }^{9}$ Diagnostic and Statistical Manual of Mental Disorders, 2nd ed. Washington, DC: American Psychiatric Association, 1968.

${ }^{10}$ Mirsky AF, Primac DW, Marsan CA, Rosvold HE, Stevens JR. A comparison of the psychological test performance of patients with focal and non-focal epilepsy. Exper Neurol 1960;2:75-90.

"Mignone RJ, Donnelly EF, Sadowsky D. Psychological and neurological comparisons of psychomotor and non-psychomotor epileptics. Epilepsia 1970;11:34559.

12 McIntyre MJ, Pritchard PB, Lombroso CT. Left and right temporal lobe epileptics: a controlled investigation of some psychological differences. Epilepsia 1976;17:377-86.

${ }^{13}$ Meyer DR, Ruth RA, Lavond DG. The septal social cohesiveness effect: its robustness and main determinants. Physiol Behav 1978;21:1027-9.

${ }^{14}$ Blumer D, Walker AE. Sexual behavior in temporal lobe epilepsy. Arch Neurol 1967;16:37-43.

15 Dongier S. Statistical study of clinical and EEG manifestations of 546 psychotic episodes occurring in 516 epileptics between clinical seizures Epilepsia 1959;1:117-42.

${ }^{16}$ Bear D. The temporal lobes: an approach to the study of organic behavioral changes. Handbook of Behavioral Neurology 1979, Vol 2. Gazzanigel M, ed. London: Plenum Press.

17 Jones B, Mishkin M. Limbic lesions and the problem of stimulus-reinforcement associations. Exper Neurol 1972;36:362-77.

${ }^{18}$ Blumer D. Treatment of patients with seizure disorder referred because of psychiatric complications. $J$ McLean Hospital, 1977, Special issue: 53-73.

${ }^{19}$ Dicks D, Myers RE, Kling A. Uncus and amygdala lesions: effects on social behavior in the free ranging monkey. Science 1969;165:69-81. 